\title{
Neat but not gaudy: planning and creating an electronic induction tutorial at the University of Bath
}

\author{
Katy Jordan and Ian Badger
}

\section{Authors}

Katy Jordan is Faculty Librarian for Engineering \& Design at the University of Bath, and chairs the library's Publications Group.

Ian Badger was Graduate Trainee 2002-3 at University of Bath Library \& Learning Centre, and is now at library school at Manchester Metropolitan University.

Email: K.M.Jordan@bath.ac.uk

\begin{abstract}
A team of staff at the University of Bath Library and Learning Centre has developed a web-based e-learning package for library induction. This article charts the whole planning process, setting it within context of e-learning developments at the parent institution and throughout the wider academic environment. It shows how input from academic staff and librarians have shaped the content of the induction tutorial, while its structure and presentation was inspired by examples of good practice elsewhere in the academic library world.
\end{abstract}

\section{Acknowledgements}

Major contributors to this project were, within the Library, Tony Holbrook, Linda Humphreys, Kate Robinson, Isobel Stark \& Claire Tylee. Academic contributors were Dr Steve Wharton of the Department of European Studies \& Modern Languages and Dr Kate Blackmon of the School of Management.

\section{Introduction}

Like many UK universities, the University of Bath is beginning to use e-learning as one solution for the problems of growing student numbers, lack of teaching space and time, and pressure on staff. We in the Library have been aware of these problems for some years now. We find our attempts to get teaching time and space for traditional induction and information skills training sessions have been thwarted for just those reasons. So we have been looking for other ways to reach our users and guide them towards the skills and resources they need for their studies and research.

E-learning seemed the obvious way to go. In its Learning and Teaching Strategy, the University of Bath encourages its departments "to facilitate the use of web-based learning materials [and] to place relevant learning materials on the web pages to increase accessibility to students." (University of Bath 2002) Of course, in the Library we have been using the Web for years to make information and resources available to our students. But what we lacked was some kind of interactive package that students could use independently, and we needed this more and more urgently.

So it was that the E-Information Skills Task Group was born. Its brief was to investigate current practice in other academic libraries, from data providers, and in our home institution. Based on these findings it was to recommend the most practical 
way forward for induction, WebCat training and further information skills training. The group initially comprised the head of Reader Services and the three Faculty librarians (including me), but expanded later to include a Management librarian and the Graduate trainee. We met first in March 2003, and worked towards producing a final report in September that year. But both group remit and timescale were destined to change and adapt in response to our findings.

\section{Current practice in e-information skills}

Our first task was to find out what other academic libraries were doing in this area. A search of the literature revealed little or nothing written specifically on e-information skills packages, which was all the more surprising when a trawl of library websites revealed some impressive virtual tours and information skills packages. Clearly librarians were working hard in this area, apparently too busy to write up their experiences in the professional journals. So we emailed lis-link asking if people had produced e-infoskills packages, whether they used commercial packages or created their own, what tools they used, and what they saw as the advantages and disadvantages. Sifting the various responses (summarised in more detail in Jordan 2000) revealed that

- Most libraries were using web pages (rather than Virtual Learning Environments (VLEs) to deliver information skills training

- E-infoskills packages were most useful when they were purpose-written, rather than generic

- It was important to use the full interactive and multimedia capabilities of the web. Otherwise you would simply end up with a workbook on the web.

Next we looked at individual online resources to assess what they provided as readymade training materials. Provision varied wildly from nothing at all (some commercial sites), through simple presentations using webcams and screenshots, to a good interactive tutorial with quiz questions (Beilstein $\mathrm{XFT}^{1}$ ). This exercise revealed that

- Interactive tutorials were best; other 'tutorials' were helpful but no substitute for a purpose-written package

- Whatever we produce in-house should be adaptable for different disciplines, and include some element of assessment

We also took a careful look at what was happening elsewhere in the University of Bath. University Departments were using e-learning methods to different extents. The Centre for Development of New Technologies in Learning (CDNTL) was the lead body, employing two Learning Support Officers who proved very helpful to us. One or two departments were using VLEs and other e-learning methods significantly to deliver teaching. Unsurprisingly, our distance learning courses also made extensive use of VLEs. More importantly for us, the Teaching \& Learning Committee had funding for development of just such learning resources as we were planning.

\footnotetext{
${ }^{1}$ http://xft.mimas.ac.uk/
} 


\section{Bidding for funding}

All our research pointed towards the need to develop e-learning packages in-house, tailored to the needs of our users, and based on the web using multimedia and interactive elements. We had library staff with the skills we needed, but such a demanding project would cost a lot in terms of staff time. It was clear that we should submit a bid for project funding to the teaching \& learning committee. The bid was aimed at funding induction and WebCat training, and fell into two sections:-

- Library induction tutorial. We asked for funding for 14 days of academic-related staff time.

- Catalogue training tutorial. We asked for 28 days of academic-related staff time.

The bid demonstrated the need at Bath for such e-learning packages, and included statements from academics in support of the project: "Students are often overwhelmed by the choice of learning materials online and physically in the library. A self-paced online tutorial would help them understand and exploit the full range of services and resources, both when they first use the library, and again when they need to refresh and/or expand these skills for particular projects or coursework ${ }^{2}$."

\section{Surveying information skills: what we do, what we want to do ${ }^{3}$}

While waiting for a response to the bid, we continued finding out about information skills teaching at the University of Bath. Any e-information skills packages would augment the current teaching sessions given by subject librarians, and help those students who might not be able to come to the sessions. It was important to find out people's opinions on the content and structure to be included, and we chose to do this by carrying out a number of surveys. We designed these to find out about the current Induction sessions given to students in their opening week at the University, and to clarify expectations of an online package.

We carried out three separate surveys, each aimed at a different section of staff. The first group was Subject Librarians who currently give the Library induction sessions, and who would have the major input into the online induction. The second group was Level 2 issue desk and information point staff who bear the brunt of induction-related enquiries. The last group was made up of the Library Representatives, academic staff who are the link between departments and subject librarians.

The subject librarians were asked what they covered during their induction sessions, what they left out because of lack of time, and what they considered unsuitable for an induction. The Level 2 staff were asked about the questions they receive at the start of a new academic year: this would highlight the information that new students feel they need when they start to use the Library \& Learning Centre. The library representatives were asked about the availability and content of inductions held in the academic departments, and what they expected of the Library's induction sessions.

Responses showed that the current induction sessions given at the library are brief, and that some librarians do not have as much time as they would like. Lack of time and potential disturbance to people studying in the library mean that subject librarians at Bath do not do traditional induction tours. Their inductions generally take the form

\footnotetext{
${ }^{2}$ Comment from Dr Kate Blackmon, School of Management, University of Bath.

${ }^{3}$ This section is adapted from Ian Badger's project report, compiled during his graduate traineeship at the University of Bath Library.
} 
of a short presentation to students as part of a large instruction to campus services. The presentations include guidance on where to get further help, directional information and a summary of basic library services. All librarians would like followup sessions, and all mentioned particular services that they would like to introduce to students at a later stage. The information from the academic departments varied: some had departmental sessions and others did not. The Library representatives highlighted some issues not generally mentioned by the subject librarians, such as plagiarism and the reliability of information found on the Internet.

\section{Induction e-tutorial: the brief}

By July 2003 we had been told that our bid for funding was successful, and that we could begin to produce some electronic learning materials. At this point the group's remit changed from simply advising on future developments to actually planning and facilitating them. We decided to start with the induction package, and to develop the WebCat tutorial later. This would then coincide with the installation of $i$ Link, which was to replace our current WebCat in summer 2004.

Working with the responses to the various surveys, all subject librarians contributed to a list of elements which should be included in the induction tutorial. These were:

- Welcome

- Library card and PIN - how to get them, what they are for

- Opening hours

- Arrangement of floors

- The collections: books, journals, videos, newspapers...

- Classification scheme

- Library space: group study, private study etc

- Loan categories and how to borrow

- WebCat and reading lists

- Renewals, reservations, fines

- Self-issue machine

- Photocopying and printing

- Copyright

- Plagiarism

- Where to get help

We asked the Library webmaster, Isobel Stark, who is also a subject librarian, to produce the induction tutorial for the start of the first semester in October. We specified that we wanted something aimed at first-year students, to be friendly, brief and informative. It should link out to the fuller information on our library website where appropriate, and should contain a self-test element. It should also be available in an accessible viewing version for students with visual impairment. 


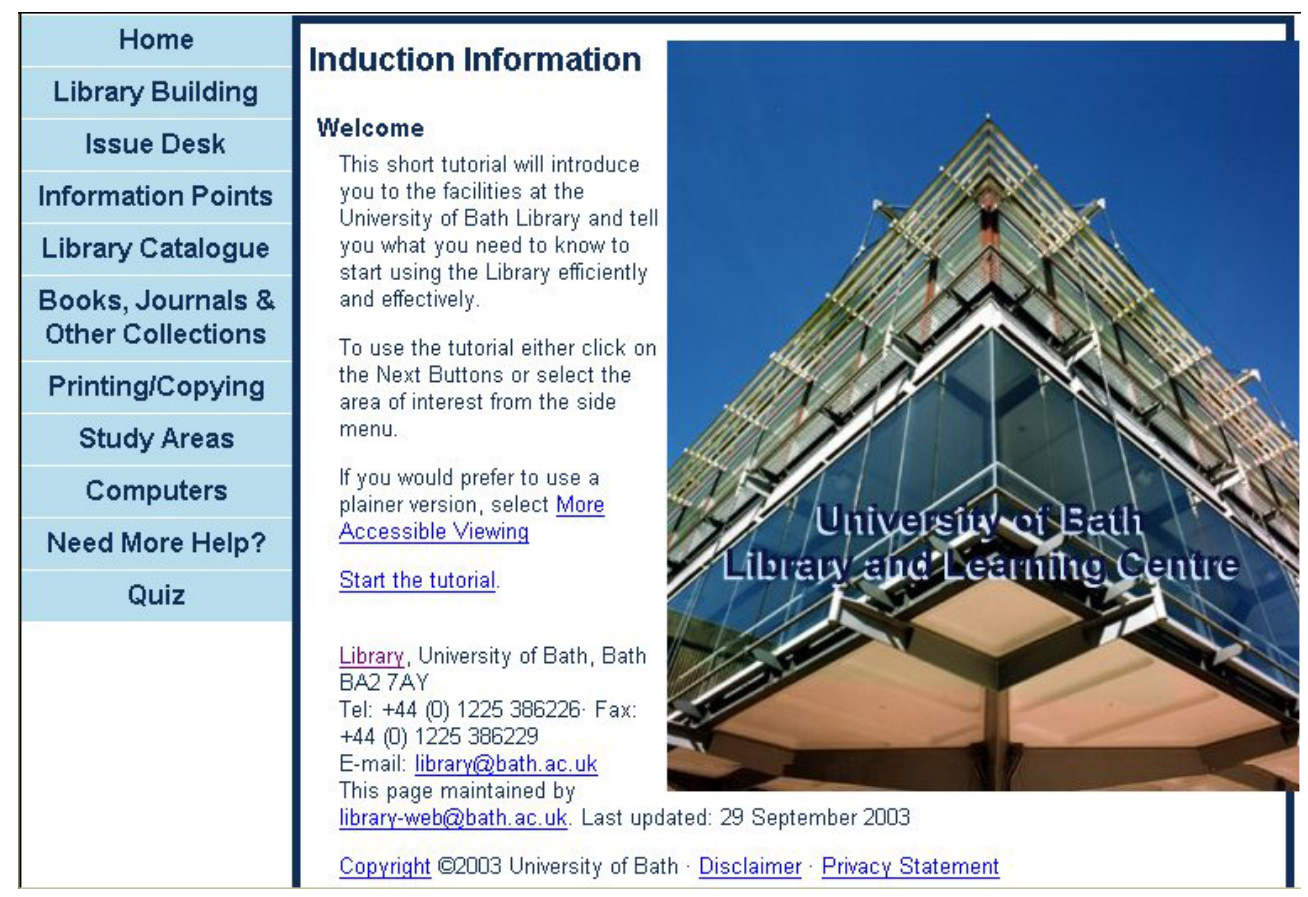

Figure 1: The initial welcome page of the induction tutorial

\section{Induction e-tutorial: the end product}

With impressive speed our Webmaster put together a very neat induction package, available to view at: http://www.bath.ac.uk/library/induction/. It is divided up into broad sections, which lead to pages of up to six typical Fresher questions. Each of these are grouped around a six-celled 'revolving door' (the Library's trademark revolving door has been a focus of fear and queues since 1995) with a central pivot (marked "?") which leads through to the self-test quiz.

\section{The Library Building \\ The Library is : \\ - a physical building \\ - a physical collection of books, journals and other material \\ - a virtual collection of online resources and information which can be found at http://mww. bath.ac. uk/library/}

To find out more about the library as a physical building, choose the questions you want the answers to from our revolving door.

To test yourself, select the question mark.

Library, University of Bath, Bath BA2 $7 \mathrm{AY}$

Tel: +44 (0) 1225386226 . Fax: +44 (0) 1225386229

E-mail: library@bath.ac.uk

This page maintained by library-web@bath.ac.uk. Last updated: 29 September 2003

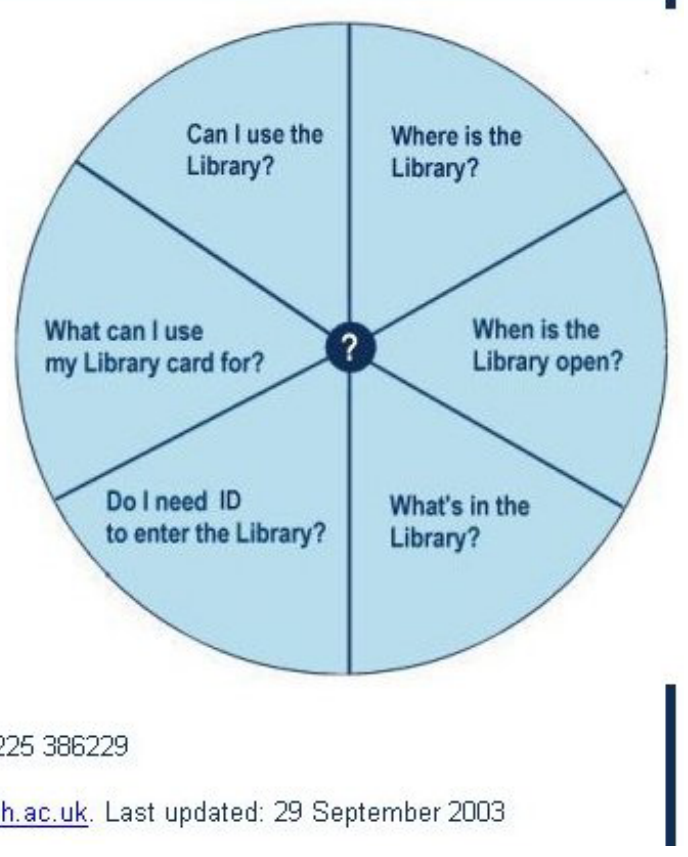

Figure 2: One of the six sections. 
The answers are written in the plainest of Plain English, and links throughout lead to more detail on the main website.

The eagle-eyed will note that the induction tutorial is a simple website, with no animated graphics, audio or video. This is in part because the whole package is carefully set up to display effectively in accessible viewing mode. We also felt that this induction package should be a quick-reference tool, which students can dip into whenever they need information. Animation can be fun the first time it appears, but if it serves no useful function it simply delays the process of finding direct answers to simple questions. So our induction tutorial is simply designed to do a specific job with the minimum of fuss.

Subject librarians are pleased with the package, and have found it a valuable tool for induction during October 2003. Some used it as part of formal teaching sessions ('now you have 15 minutes to work through the induction tutorial'); others simply pointed students towards it as a good starting point for learning to use the library. It is not, of course, the single answer to effective library induction. Students need a series of tools to help them learn to use the library. The induction tutorial now takes its place alongside our 'concertina' guide ${ }^{4}$, our suite of handouts, the extensive library website, our formal teaching sessions and our skilled and helpful library staff.

\section{The way forward}

This is only the first step on our journey towards a set of electronic information skills tutorials. We await the arrival of iLink: its user-friendliness will dictate the shape and style of the tutorial we create. We have already drawn up the content and structure of more advanced information skills modules that subject librarians will be able to adapt to their particular departments and resources. Meanwhile the technology and tools continue to grow and change, and taking advantage of these is the challenge for the near future.

\section{Bibliography}

Jordan, Katy (2003). E-Information Skills: investigating current developments in electronic information skills training within the Library and Information Profession. Libraries for Nursing Bulletin, 23 (2), 19-24.

University of Bath (2002). Learning and Teaching Strategy 2002/03 - 2004/05. URL: http://www.bath.ac.uk/quality-support/lts2002.htm [26 Feb 2004]

\section{WORD COUNT: 2230}

\footnotetext{
${ }^{4}$ A credit-card-sized foldout guide giving basic information about the Library, given out in a credit card walled with every library card we make.
} 